\title{
Observational Study to Assess the Safety and Clinical Effectiveness of the Hospital Universitario de Canarias Massive Transfusion Protocol
}

\author{
González Fariña $\mathrm{V}^{1 *}$, Martín Lorenzo $\mathrm{MC}^{1}$, Borges Jurado $\mathrm{R}^{2}$, Jiménez Rivera J ${ }^{3}$, Raya Sánchez $\mathrm{JM}^{4}$, Brouard $\mathrm{MT}^{3}$, \\ Arribas-Carrión JC ${ }^{1}$, Montón Giménez $\mathrm{N}^{1}$ \\ ${ }^{1}$ Department of Anesthesia, Hospital Universitario de Canarias, San Cristóbal de La Laguna, Spain \\ ${ }^{2}$ Department of Physical Medicine and Pharmacology, La Laguna University, San Cristóbal de La Laguna, Spain \\ ${ }^{3}$ Department of Intensive Medicine, Hospital Universitario de Canarias, San Cristóbal de La Laguna, Spain \\ ${ }^{4}$ Department of Hematology ,Hospital Universitario de Canarias, San Cristóbal de La Laguna, Spain \\ ${ }^{*}$ Correspondence to: González Fariña V, Department of Anesthesia, Hospital Universitario de Canarias, San Cristóbal de La Laguna, Spain; \\ E-mail: vanefari@outlook.com
}

Received: September 15, 2018; Accepted: September 27, 2018; Published: October 02, 2018;

\begin{abstract}
Introduction: Massive haemorrhage $(\mathrm{MH})$ is a frequent entity and leads to high mortality rates. The early administration of blood products with high ratios following massive haemorrhage protocols (MHP) has proven to reduce mortality and transfusion of blood components.

Objectives: evaluate the safety and effectiveness of newly implemented MHP for surgical patients with MH and study mortality at 30 day of the haemorrhagic process.

Methods: a new massive haemorrhage protocol was developed and it was based on the early administration of blood products with a 3: 3: 1 ratio (redblood cells, fresh frozen plasma, platelet). It was a prospective study in which 34 patients with massive haemorrhage were included. The patients were divided in two groups (implementation or non-implementation of the new protocol).

Results: the application of the protocol has not led to a decrease in the mortality rate or in the administration of red blood products and hemostatic drugs. Though there was an increase in the administration of procoagulant factors, but it was not associated with a higher incidence of adverse effects and complications related to mass transfusion.
\end{abstract}

Key words: massive haemorrhage, transfusion, protocol

\section{Introduction}

Massive transfusion refers to the infusion of a large volume of blood products over a relatively short period of time, in response to a clinical situation of massive haemorrhage $(\mathrm{MH})$. Massive bleeding leads to high mortality rates, partly as a result of the "lethal triad" (hypothermia, acidosis and coagulopathy) [1-2].

$\mathrm{MH}$ can occur from a variety of causes, both traumatic and nontraumatic (rupture of an aortic aneurysm, perioperative complications of several surgeries, gastrointestinal bleeding, uterine atony, etc.) [3].

The implementation of massive haemorrhage protocols (MHPs) has proven to reduce mortality and transfusion of blood components. The administration of high plasma and platelet proportions in relation to red blood cell concentrates, together with the rapid onset of transfusion, enables coagulopathy to be prevented or treated early [4-5]. The HEMOMAS consensus document suggests that transfusion protocols in MH should work with an alarm system established in the haemotherapy commissions of each hospital, as a multidisciplinary consensual protocol, regularly analyzing its efficacy and safety [6].
The MHPs were designed to focus primarily on the polytraumatized patient, without considering another type of cause of $\mathrm{MH}$ [7-8]. It is not yet clear whether the same protocol can be used in patients with HM regardless of the cause.

In an effort to standardise the care of patients with perioperative haemorrhage, in our hospital we have developed the "Massive haemorrhage protocol of the Hospital Universitario Canarias" which was approved by the Hospital Transfusions Committee. This is based above all on the recommendations of the HEMOMAS document and the European Guide for the management of severe haemorrhages and coagulopathy in trauma patients.

This protocol is based on the early administration of blood products with a 3: 3: 1 ratio (red-blood cells, fresh frozen plasma, and platelet), damage control, restrictive fluid resuscitation and coagulation monitoring [9]. Its objectives are to reduce variability in clinical practice, try to prevent and treat coagulopathy associated with massive bleeding and ensure a safe supply of blood products. 


\section{Methods}

\section{Study Population}

Patients were recruited between January 2015 and January 2017.

A prospective observational descriptive study was conducted to evaluate the safety and effectiveness of the implementation of an MHP in a third level, hospital. This protocol was approved by the Ethics and Clinical Research Committee of the Hospital Universitario de Canarias.

The study was conducted following the standards of good clinical practice for trials with medical products in the European Community and the Declaration of Helsinki on medical research involving human subjects. Registration was completed at ClinicalTrials.gov (NCT03074890).

All $\mathrm{MH}$ patients undergoing any elective or emergency surgical procedure were included, 34 in total. Exclusion criteria were patients under 18 years of age, patients with congenital or acquired coagulation factor deficiencies and congenital platelet aggregation disorders. All patients received information from the study and gave their written consent.

Patients were intervened and treated by the specialist physicians in charge at the time of the MH. The study population was divided into 2 groups based on whether or not the MHP was implemented. MHP group: patients on whom the protocol was activated. Non-MHP group: patients who were transfused with no protocol guidance.

\section{Massive haemorrhage protocol}

Massive haemorrhage was identified with one or more of the following criteria: (1) replacement of whole blood volume in a $24-\mathrm{h}$ period (7\% of ideal body weight in adults); (2) replacement of $50 \%$ of blood volume in a 3-h period or (3) blood loss $\geq 150 \mathrm{~mL} / \mathrm{min}$ for 10 consecutive minutes.

HP is summarized in Figure 1.
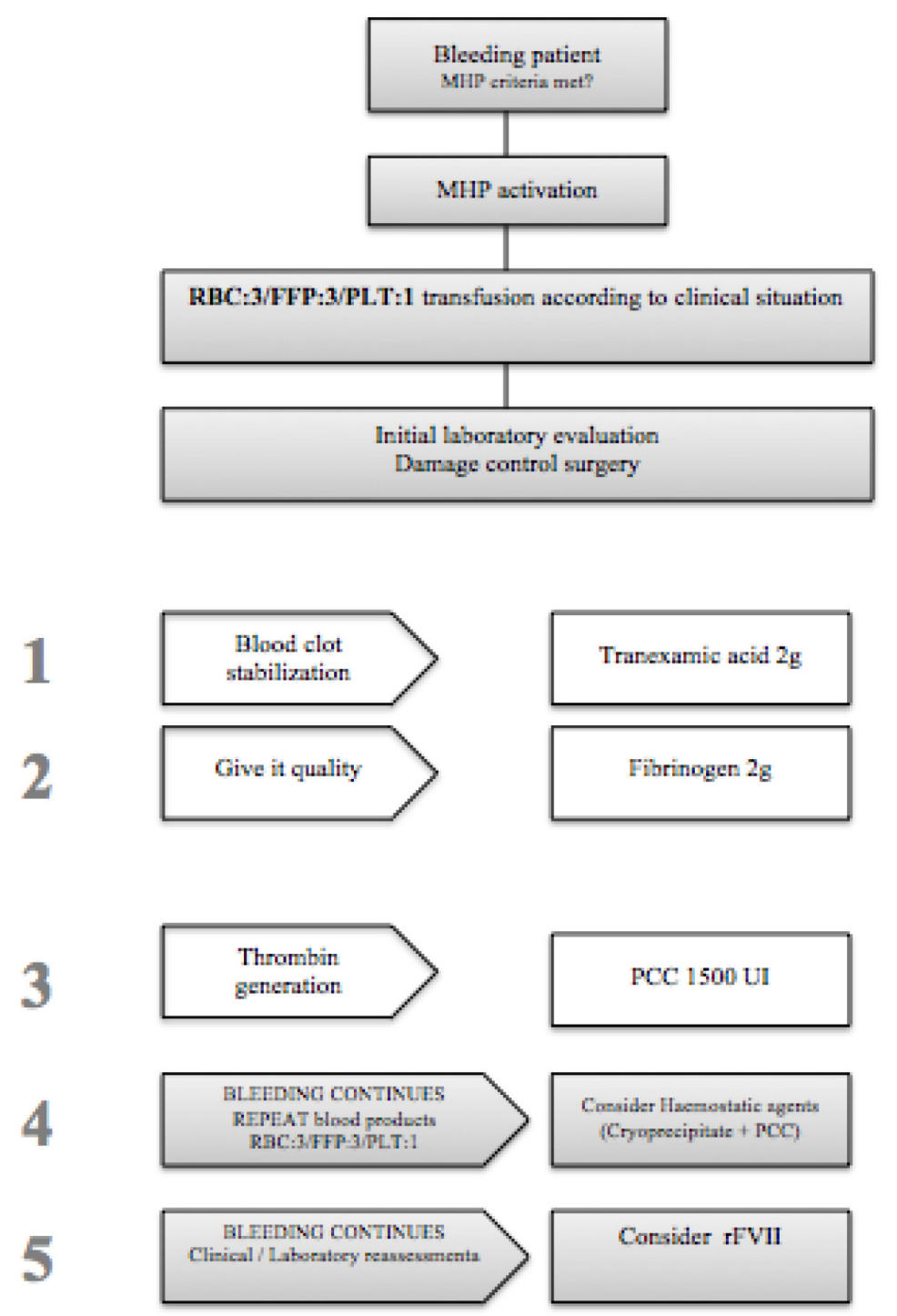
The activation of MHP was the responsibility of the anaesthesiologist or the emergency team.

Once the protocol was activated, 3 packed red-blood cells (RBC), 3 packed fresh frozen plasma (FFP) and one packed unit of platelet (PLT) were administered. At the same time, factors related to lethal triad (hypothermia and acidosis), hydroelectrolytic alterations were corrected and the cause of bleeding was treated while the appropriate complementary tests were performed. In addition, $2 \mathrm{~g}$ of tranexamic acid was administered to stabilise the clot, and $2 \mathrm{~g}$ of fibrinogen was added to give it quality. Prothrombin complexes were administered to generate thrombin. Laboratory results were not awaited to begin transfusion. If after all this the bleeding continued, more RBC, FFP and other packed PLT were transfused and an ampoule of calcium plus cryoprecipitates was added. If the bleeding persisted, activated Factor VII was administered at a dose of $60-90 \mathrm{mcg} / \mathrm{kg}$.

In ourhospitalwedonothaveviscolastictests(thromboelastometry/ thromboelastography) for clinical decision making within MHP.

The implementation of MHP required the multidisciplinary cooperation of several Hospital Services (Anaesthesiology, Haematology and Intensive Care).

Doppler echocardiography of supra-aortic trunks and central venous accesses was performed to assess thrombotic phenomena in patients who received a massive transfusion in the first $48-72$ hours.

\section{Study end points}

The primary objective of the study was to evaluate the safety and effectiveness of newly implemented MHP for surgical patients with traumatic and non-traumatic $\mathrm{MH}$.

Secondary objectives included determining mortality at 30 days, comparing outcomes between patients who received transfusion of blood products according to MHP and those who did not, and assessing the incidence of adverse reactions with high rates of blood products.

\section{Statistical Analyses}

A descriptive statistic was performed for all variables included in the data collection notebook.

Qualitative variables were expressed with absolute frequencies and percentages and quantitative and ordinal variables with means and standard deviations. Proportion comparisons were made with Fisher's chi-square or exact tests, as appropriate. Comparisons of two groups in quantitative and ordinal variables were made with Mann-Whitney tests; comparisons of groups controlling for confounding variables were made with ANOVA, as appropriate. Probability values below 0.05 were considered significant. Analyses were performed with the SPSS statistical package version 17.0 (IBM SPSS, Chicago, IL, USA).

Data were expressed in frequencies and percentages for categorical variables, and in means with their $95 \%$ confidence intervals for numerical variables.

Demographic data (age, sex, weight, height, and ASA) were compared among the target groups to confirm their homogeneity.

\section{Results}

\section{Patient characteristics}

We recruited a total of 34 patients with $\mathrm{MH}$ who underwent surgical procedures. 20 of them (59\%) received blood products according to the MHP and the remaining 14 (41\%) according to the criteria of the anestheologist in charge.

The mean age of the MHP group was $55 \pm 19$ years, while in the non-MHP group $57 \pm 18$ years. No statistically significant differences were observed in the demographic and clinical data, nor in the laboratory results carried out prior to the intervention, being both groups homogeneous and comparable to each other.

Table 1 describes the basic characteristics of the patients.

Table 1. Baseline characteristics of patients with massive hemorrhage. $(\mathrm{n}=34)$.

\begin{tabular}{|c|c|c|c|}
\hline Variable & $\begin{array}{l}\text { MHP Group (n } \\
\quad=20)\end{array}$ & $\begin{array}{l}\text { Non-MHP } \\
\text { Group (n } \\
=14)\end{array}$ & $\mathbf{P}$ \\
\hline Age (years) & $55 \pm 19$ & $57 \pm 18$ & 0,83 \\
\hline Sex (males) - n (\%) & $12(60)$ & $9(64)$ & 1,0 \\
\hline BMI $\left(\mathrm{kg} / \mathrm{m}^{2}\right)$ & $26 \pm 4$ & $28 \pm 5$ & 0,57 \\
\hline ASA-n (\%) & $3,0 \pm 1$ & $2,67 \pm 1$ & 0,42 \\
\hline APACHE II & $13 \pm 6$ & $13 \pm 7$ & 0,93 \\
\hline Antiplatelet Agents - n $(\%)$ & $4(20)$ & $4(26,7)$ & 0,43 \\
\hline OAC $-\mathrm{n}(\%)$ & $5(25)$ & $1(6,7)$ & 0,2 \\
\hline Hepatopathology $-\mathrm{n}(\%)$ & $2(10)$ & $0(0)$ & 0,5 \\
\hline Haemoglobin (g/dL) & $12,3 \pm 2,2$ & $10,8 \pm 2,6$ & 0,09 \\
\hline Platelet $10^{3} / \mathrm{mm}^{3}$ & $120 \pm 52$ & $266 \pm 163$ & 0,98 \\
\hline pH & $7,33 \pm 0,12$ & $7,37 \pm 0,12$ & 0,42 \\
\hline Lactic acid (mmol/L) & $2,87 \pm 4,6$ & $1,42 \pm 0,79$ & 0,47 \\
\hline Base deficit (mmol/L) & $-3,46 \pm 4,74$ & $-1,3 \pm 3$ & 0,4 \\
\hline PT (\%) & $87,8 \pm 21,11$ & $91 \pm 13$ & 0,9 \\
\hline INR & $1,12 \pm 0,32$ & $1 \pm 0,15$ & 0,78 \\
\hline aPTT (seg) & $35,74 \pm 7,28$ & $37,8 \pm 3$ & 0,72 \\
\hline Fibrinogen (mg/dL) & $474 \pm 162$ & $515,8 \pm 219$ & 0,73 \\
\hline
\end{tabular}

Variable values are denoted as mean \pm standard deviation. aPTT $=$ activated partial thromboplastin time: ASA: American Society of Anesthesiologists; BMI: body mass index; INR = international normalized ratio; OAC: oral anticoagulants; $\mathrm{PT}=$ prothrombin time.

Ninety-four percent of patients had non-traumatic $\mathrm{MH}$ and only $6 \%$ of patients had MH secondary to trauma (Table 2).

Cardiovascular surgery was the main cause of HM (35 and 13.3\%), followed by abdominal surgery (20\%).

Massive bleeding occurred during emergency surgery in $60 \%$ of subjects in the MHP group and $40 \%$ in the non-MHP group. 
The estimated intraoperative bleeding was similar in both groups. In the MHP group there was an estimated mean bleeding of $2640 \pm$ $1467 \mathrm{~mL}$, and in the non-MHP group of $2090 \pm 866 \mathrm{~mL}$.

Table 2. Intraoperative period variables

\begin{tabular}{|c|c|c|c|}
\hline & $\begin{array}{c}\text { MHP Group (n } \\
=20)\end{array}$ & $\begin{array}{c}\text { Non-MHP Group } \\
(n=14)\end{array}$ & $\mathbf{P}$ \\
\hline Patient type $-\mathrm{n}(\%)$ & & & 0,1 \\
\hline Trauma surgery & $0(0)$ & $2(13,3)$ & \\
\hline Orthopedics surgery & $1(5)$ & $1(6,7)$ & \\
\hline Abdominal surgery & $4(20)$ & $3(20)$ & \\
\hline Vascular surgery & $4(20)$ & $0(0)$ & \\
\hline Cardiovascular surgery & $7(35)$ & $2(13,3)$ & \\
\hline Other surgeries & $4(20)$ & $7(46,7)$ & \\
\hline $\begin{array}{l}\text { Type of intervention } \\
-\mathrm{n}(\%)\end{array}$ & & & 0,24 \\
\hline Elective surgery & $8(40)$ & $9(60)$ & \\
\hline Urgent surgery & $12(60)$ & $6(40)$ & \\
\hline $\begin{array}{l}\text { Intraoperative } \\
\text { estimated bleeding } \\
(\mathrm{mL})\end{array}$ & $2640 \pm 1467$ & $2090 \pm 866$ & 0,24 \\
\hline pRBC (units) & $4 \pm 2$ & $3 \pm 1$ & 0,18 \\
\hline pFPP (units) & $3 \pm 2$ & $1 \pm 1$ & 0,1 \\
\hline pPLT (units) & $0,7 \pm 0,6$ & $0,3 \pm 0,6$ & 0,18 \\
\hline Fibrinogen (g) & $1,5 \pm 0,9$ & $0,9 \pm 1,2$ & 0,07 \\
\hline TXA (g) & $2,5 \pm 1$ & $1,6 \pm 1$ & 0,03 \\
\hline PCC (UI) & $900 \pm 911$ & $333 \pm 523$ & 0,07 \\
\hline Cryoprecipitate (UI) & 0 & 0 & 1,0 \\
\hline rFVII $(\mu \mathrm{g})$ & 0 & 0 & 1,0 \\
\hline pH & $7,25 \pm 0,13$ & $7,32 \pm 0,04$ & 0,07 \\
\hline Lactic acid $(\mathrm{mmol} / \mathrm{L})$ & $5,24 \pm 6$ & $4,27 \pm 8,62$ & 0,25 \\
\hline
\end{tabular}

Variable values are denoted as mean \pm standard deviation. pRBC: packed red-blood cells; pFFP: packed fresh frozen plasma; pPLT: packed platelets; rFVII: recom- binant factor VII; PCC: prothrombin complex concentrate; Lactic acid (mmol/L); TXA: tranexamic acid.

The ratio of RBC: FPP transfused was higher in the MHP group than in the non-MHP group with a ratio of approximately $3: 3$. vs. 3 : 1 respectively.

Compared to the non-MHP group, the MHP group received more RBC ( 4 vs. 3 units, $\mathrm{p}=0.18$ ) more FPP ( 3 vs. 1 units, $\mathrm{p}=0.1$ ) and more platelets $(0.7 \pm 0.6$ vs. $0.3 \pm 0.6, p=0.18)$. However, the differences in the 3 parameters were not statistically significant.

The MHP group received more TXA $(2.5 \pm 1$ vs $1.6 \pm 1$ grams, $\mathrm{p}=0.03)$, more fibrinogen $(1.45 \pm 0.88$ vs $0.87 \pm 1.2 \mathrm{p}=0.07)$ and more PCC $(900 \pm 911$ vs $333 \pm 523, p=0.07)$, being statistically significant with TXA. Cryoprecipitates and activated factor VII were not administered in any of the groups.
Lactic acid increased to similar numbers in the intraoperative period in both groups (5.2 \pm 6 vs $4.2 \pm 8, \mathrm{p}=0.25)$.

During the immediate postoperative period, bleeding stopped in $85 \%$ of patients in the MHP group and in $86 \%$ in the non-MHP group. Bleeding measured in the first 24 hours was higher in the MHP group than in the non-MHP group, almost doubling in the latter group.

In terms of the amount of blood products and haemostatic drugs administered in the 48 post-operative hours, more tranexamic, fibrinogen and CCP were administered in the MHP group with statistical significance $(\mathrm{p}<0.05)$. More FPP, cryoprecipitate, rFVII and blood retrieval processes were also administered, but without reaching statistical significance. The number of RBC and PLT units was similar in both groups. This data is shown in table 3 .

Three patients had to be re-operated in the postoperative period, all of them belonging to the MHP group. But only one of them was caused by bleeding, specifically pericardial tamponade. The other reasons for reintervention were a compartment syndrome and a left bronchial leak.

Table 3. Haemoderivatives and hemostatic drugs administered postoperatively at $48 \mathrm{~h}$.

\begin{tabular}{|l|c|c|c|}
\hline & $\begin{array}{c}\text { MHP Group } \\
(\mathbf{n}=\mathbf{2 0})\end{array}$ & $\begin{array}{c}\text { Non-MHP Group } \\
(\mathbf{n}=\mathbf{1 4})\end{array}$ & P \\
\hline pRBC (units) & $5,5 \pm 4,3$ & $5,7 \pm 2,2$ & 0,29 \\
\hline pFPP (units) & $4,6 \pm 4,3$ & $2,4 \pm 2,9$ & 0,1 \\
\hline PLT (units) & $1,0 \pm 1,0$ & $0,9 \pm 1,8$ & 0,25 \\
\hline TXA (g) & $2,7 \pm 1,0$ & $0,9 \pm 1,2$ & $\mathbf{0 , 0 0 7}$ \\
\hline Fibrinogen (g) & $2,0 \pm 0,5$ & $0,9 \pm 1,3$ & $\mathbf{0 , 0 0 6}$ \\
\hline PCC (UI) & $2,6 \pm 1,9$ & $0,7 \pm 1,0$ & $\mathbf{0 , 0 0 4}$ \\
\hline Cryoprecipitate (UI) & $1,0 \pm 3,2$ & 0 & 0,6 \\
\hline rFVII ( $\mu$ g) & $526 \pm 1611$ & 0 & 0,6 \\
\hline Stop bleeding - $\mathrm{n}(\%)$ & $17(85)$ & $12(86)$ & 0,36 \\
\hline $\begin{array}{l}\text { Blood recuperator for } \\
\text { autotransfusion (ml) }\end{array}$ & $3,3 \pm 6,4$ & 0 & 0,2 \\
\hline $\begin{array}{l}\text { Estimated bleeding } \\
\text { 24 h (mL) }\end{array}$ & $541 \pm 550$ & $286 \pm 181$ & 0,18 \\
\hline $\begin{array}{l}\text { Need for reintervention } \\
\text { due to bleeding - } \mathrm{n}(\%)\end{array}$ & $1(5,3)$ & $0(0)$ & 1,0 \\
\hline
\end{tabular}

Variable values are denoted as mean \pm standard deviation. pRBC: packed red-blood cells; pFFP: packed fresh frozen plasma; pPLT: packed platelets; TXA: tranexamic acid; PCC: prothrombin complex concéntrate; rFVII: recombinant factor VII.

Postoperative analytical variables at 24 and 48 hours are shown in table 4. Haemoglobin in the 24 -hour postoperative was quite similar in both groups $(9.5 \pm 2 \mathrm{~g} / \mathrm{dL}$ in the MPH group, and $10 \pm 1 \mathrm{~g} / \mathrm{dL}$ in the non-MHP group), as well as haematocrit $(28 \% \pm 5$ for the first and $30 \% \pm 4$ for the second) and platelets (132 $\pm 114103 / \mathrm{mm} 3$ and $162 \pm$ 76 103/mm3 respectively). The same happened with some variables that measured coagulation (PT, INR, aPTT), while fibrinogen was lower in the MHP group $(296 \pm 170 \mathrm{mg} / \mathrm{dL}$ in relation to $401 \pm 214$ $\mathrm{mg} / \mathrm{dL})$ and the highest $\mathrm{D}$-dimer $(10316 \pm 22311 \mathrm{ng} / \mathrm{dL}$ in relation to $7760 \pm 11368 \mathrm{ng} / \mathrm{dL}$ ). The $\mathrm{pH}$ value was similar in both groups (MHP: $7.29 \pm 0.11$; non-MPH: $7.28 \pm 0.07)$. 
In the post-operative period at 48 hours, the numbers of platelets, fibrinogen, PT, INR and aPTT were quite similar in terms of mean and standard deviation.

Haemoglobin at 48 hours in the MHP group was significantly higher than in the non-MHP group, with an average of 9.61 and 8.46 $\mathrm{g} / \mathrm{dL}$ respectively $(\mathrm{p}=0.04)$. Hematocrit figures were also higher in the MHP group (28.85 vs $25.47 \%, \mathrm{p}=0.03$ ).
However, the lactic acid figures were higher in the MHP group, with a mean of $4 \pm 4$ being approximately $3 \pm 2$ in the non-MHP group; and the base deficit was lower in the MHP group $(-6 \pm 4)$ compared to the non-MHP group $(-5 \pm 4)$. However, these figures were not statistically significant either.

Table 4. Postoperative analyzes at 24 and 48 hours.

\begin{tabular}{|c|c|c|c|c|c|c|}
\hline & \multicolumn{3}{|c|}{$24 \mathrm{~h}$} & \multicolumn{3}{|c|}{$48 \mathrm{~h}$} \\
\hline & $\begin{array}{l}\text { MHP Group } \\
(\mathbf{n}=\mathbf{2 0})\end{array}$ & $\begin{array}{l}\text { Non-MHP Group } \\
(n=14)\end{array}$ & $\mathbf{P}$ & $\begin{array}{l}\text { MHP Group } \\
(\mathbf{n}=\mathbf{2 0})\end{array}$ & $\begin{array}{l}\text { Non-MHP Group } \\
(n=14)\end{array}$ & $\mathbf{P}$ \\
\hline Haemoglobin (g/dL) & $9,5 \pm 2,0$ & $10 \pm 1,5$ & 0,2 & $9,6 \pm 1,4$ & $8,5 \pm 0,8$ & 0,04 \\
\hline Hematocrit (\%) & $28,3 \pm 5,6$ & $30,5 \pm 4,6$ & 0,18 & $28,8 \pm 4,4$ & $25,5 \pm 2,7$ & $\mathbf{0 , 0 3}$ \\
\hline PT (\%) & $77 \pm 20$ & $84 \pm 13$ & 0,36 & $83 \pm 24$ & $93 \pm 11$ & 0,3 \\
\hline INR & $1,25 \pm 0,4$ & $1,1 \pm 1,6$ & 0,36 & $1,22 \pm 0,5$ & $1,0 \pm 1,3$ & 0,2 \\
\hline aPTT (secs) & $44,2 \pm 22,5$ & $33,8 \pm 9,1$ & 0,14 & $32,4 \pm 4,8$ & $31,0 \pm 4,8$ & 0,3 \\
\hline pH & $7,29 \pm 0,11$ & $7,28 \pm 0,07$ & 0,61 & $7,37 \pm 0,06$ & $7,35 \pm 0,08$ & 0,7 \\
\hline Lactic acid (mmol/L) & $4,4 \pm 3,9$ & $2,7 \pm 1,8$ & 0,11 & $2,3 \pm 2,2$ & $2,3 \pm 4,1$ & 0,2 \\
\hline Base Deficit $(\mathrm{mmol} / \mathrm{L})$ & $-5,2 \pm 3,9$ & $-6 \pm 3,9$ & 0,4 & $-1,65 \pm 3,66$ & $-3,4 \pm 3,33$ & 0,1 \\
\hline CPK-NAC (U/L) & $359 \pm 361$ & $645 \pm 468$ & 0,09 & $3233 \pm 7554$ & $1944 \pm 2183$ & 0,7 \\
\hline
\end{tabular}

Variable values are denoted as mean \pm standard deviation. aPTT $=$ activated partial thromboplastin time; CPK-NAC $=$ creatine kinase INR $=$ international normalized ratiol; PLT: Platelets; PT = prothrombin time.

Once the protocol was implemented only $15 \%$ of patients reached phase $2,75 \%$ reached phase 3 , and $10 \%$ reached phase 5 (Graph 1).

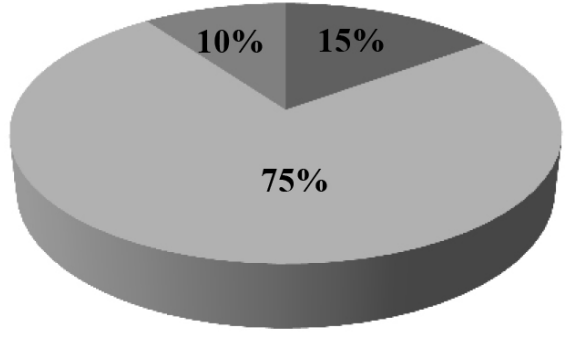

- Phase 2

Phase 3

Phase 5

Figure 1. Adherence to MHP

Table 5 describes minor and major bleeding events (decrease in $\mathrm{Hb}>2 \mathrm{~g} / \mathrm{dL}$ or requiring reintervention for bleeding). Major (26\% vs $7 \% ; \mathrm{p}=0.2$ ) and minor ( $32 \%$ vs $13 \%, \mathrm{p}=0.2$ ) bleeding events were more frequent in the MHP group without statistical significance.

The presence of thrombotic episodes was assessed by clinical and doppler ultrasound. Doppler ultrasound was only possible for 11 patients (55\%) in the MPH group and $9(64 \%)$ in the non-MHP group.
In the MPH group, none of the patients showed thrombosis, while in the non-MHP group, 5 (35\%) showed thrombotic symptoms (supraaortic trunk thrombosis in one patient, and central venous access thrombosis in 3). However, despite these percentage differences, there were no significant differences.

Table 6 describes adverse effects and complications that may be related to mass transfusion (Table 6).

Non-immunological reactions occurred in $100 \%$ of patients in the non-MHP group and in 95\% of patients in the MHP group. Among these the most frequent were thrombocytopenia (80\% in the MHP group versus $47 \%$ in the non-MHP group; $\mathrm{p}=<0.04)$, hypocalcemia ( $85 \%$ and $93 \%$ respectively), and acidosis (65\% and $73 \%$ ).

Infectious complications occurred in 2 patients in the MHP group (pneumonia) and in a single patient in the non-MHP group (tracheobronchitis after 10 days).

Immunological reactions occurred in 10\% of patients in the MHP group and in $20 \%$ of patients in the non-MHP group. And in all cases the reaction was lung injury, specifically transfusion-related acute lung injury or TRALI. 
Table 5. Haemorrhage and thrombotic events

\begin{tabular}{|l|c|c|c|}
\hline & $\begin{array}{c}\text { MHP Group } \\
(\mathbf{n}=\mathbf{2 0})\end{array}$ & $\begin{array}{c}\text { Non-MHP Group } \\
(\mathbf{n}=\mathbf{1 4})\end{array}$ & P \\
\hline Minor hemorrhagic — n (\%) & $6(32)$ & $2(13)$ & 0,2 \\
\hline Major hemorrhagic — n (\%) & $5(26)$ & $1(7)$ & 0,2 \\
\hline $\begin{array}{l}\text { Doppler echocardiography- } \\
\text { n (\%) }\end{array}$ & $11(55)$ & $9(60)$ & 0,76 \\
\hline Thrombosis SAT-n (\%) & $0(0)$ & $2(14)$ & 0,2 \\
\hline $\begin{array}{l}\text { Central venous access } \\
\text { thrombosis - n (\%) }\end{array}$ & $0(0)$ & $3(21)$ & 0,74 \\
\hline TVP-n (\%) & $0(0)$ & $0(0)$ & \\
\hline $\begin{array}{l}\text { Pulmonary embolism - n } \\
\text { (\%) }\end{array}$ & $0(0)$ & $0(0)$ & \\
\hline TIA-n (\%) & $0(0)$ & $0(0)$ & $0(0)$ \\
\hline AMI-n (\%) & $0(0)$ & & \\
\hline
\end{tabular}

Variable values are denoted as mean \pm standard deviation. AMI $=$ acute myocardial infarction; SAT $=$ supraaortic trunk thrombosis ; TIA: transient ischemic attak; TVP = Deep venous thrombosis.

Table 6. Complications and adverse effects of the patients with massive haemorrhage

\begin{tabular}{|c|c|c|c|}
\hline & $\begin{array}{l}\text { MHP Group } \\
\quad(\mathbf{n}=\mathbf{2 0})\end{array}$ & $\begin{array}{l}\text { Non-MHP Group } \\
\qquad(\mathrm{n}=\mathbf{2 0})\end{array}$ & $\mathbf{P}$ \\
\hline $\begin{array}{l}\text { Non-immunological } \\
\text { reactions - n (\%) }\end{array}$ & $19(95)$ & $14(100)$ & 1,0 \\
\hline Hypothermia - n (\%) & $6(30)$ & $5(33)$ & 1,0 \\
\hline Coagulopathy-n (\%) & $7(35)$ & $1(6,7)$ & 0,1 \\
\hline $\begin{array}{l}\text { Thrombocytopenia - n } \\
(\%)\end{array}$ & $16(80)$ & $7(47)$ & 0,04 \\
\hline Acidosis-n (\%) & $13(65)$ & $11(73)$ & 0,72 \\
\hline Hypocalcemia-n (\%) & $17(85)$ & $14(93)$ & 0,62 \\
\hline Hyperkalemia-n (\%) & $2(10)$ & $0(0)$ & 0,5 \\
\hline TACO-n (\%) & $10(50)$ & $5(33)$ & 0,32 \\
\hline Infections-n (\%) & $2(10)$ & $1(6,7)$ & 1,0 \\
\hline $\begin{array}{l}\text { Immunological } \\
\text { reactions-n (\%) }\end{array}$ & $2(10)$ & $3(20)$ & 0,63 \\
\hline $\begin{array}{l}\text { Hemolytic reactions-n } \\
(\%)\end{array}$ & $0(0)$ & $0(0)$ & 1 \\
\hline Allergic reactions-n (\%) & $0(0)$ & $0(0)$ & 1 \\
\hline $\begin{array}{l}\text { Pulmonary injury-n } \\
(\%)\end{array}$ & $2(10)$ & $3(20)$ & 0,63 \\
\hline TRALI-n (\%) & $2(10)$ & $3(20)$ & 0,63 \\
\hline
\end{tabular}

TACO: Transfusion Associated Circulatory Overload; TRALI: Transfusion Related Acute Lung Injury).

Table 7 shows mortality at 30 days and its etiology in both groups. In the MHP group there were more deaths, $40 \%(\mathrm{n}=8)$ of patients, while in the non-MHP group $21 \%(\mathrm{n}=3)$ of patients died $(\mathrm{p}=0.3)$. Only $10 \%(\mathrm{n}=2)$ of patients in the MHP group died from haemorrhagic causes, compared to $7 \%(\mathrm{n}=1)$ in the non-MHP group. The main cause of mortality in the MHP group was multiorgan failure in $20 \%(\mathrm{n}=4)$ of patients, and septic shock of abdominal origin secondary to dehiscence of anastomosis in $10 \%(\mathrm{n}=2)$. While in the non-MHP group the causes of non-hemorrhagic mortality (14\%) were heart failure and massive cerebral infarction.

Table 7. Overall mortality at 30 days of patients with massive haemorrhage

\begin{tabular}{|l|c|c|c|}
\hline Variable & $\begin{array}{c}\text { MHP Group } \\
(\mathbf{n}=\mathbf{2 0})\end{array}$ & $\begin{array}{c}\text { Non-MHP } \\
\text { Group } \\
(\mathbf{n}=\mathbf{1 4})\end{array}$ & P \\
\hline Mortality at 30 days - $\mathrm{n}(\%)$ & $8(40)$ & $3(21)$ & 0,3 \\
\hline Cause of death - n (\%) & $2(10)$ & $1(7)$ & 0,6 \\
\hline Haemorrhage & $4(20)$ & $0(0)$ & \\
\hline Organ failure & $2(10)$ & $2(14)$ & 0,3 \\
\hline Other & $16 \pm 16$ & $22 \pm 22$ & \\
\hline $\begin{array}{l}\text { Hospital lenght of stay } \\
\text { (days) }\end{array}$ & & & \\
\hline
\end{tabular}

Variable values are denoted as mean \pm standard deviation.

\section{Discussion}

The implementation of MHP in our hospital did not imply a consumption decrease of blood products. Moreover, there was a nonsignificant increase in the use of FFP in the MPH patients ( 3 units vs 1 units); there was no difference in the number of units administered of pRBC ( 4 units vs 3 units) and pPLT ( 0.7 units vs 0.3 units) between the two groups.

The average number of pRBC transfusions administered during the 48 post-operative hours was similar in both groups (5.5 units vs. 5.7 units), as was the amount of pPLT ( 1 units vs. 0.9 units); while the number of FFP was higher in the MHP group (4.6 units vs. 2.9 units).

An increase in haemostatic drug administration was observed in the MHP group. The amount of TXA administered was significantly higher in the MPH group (2.5 grams vs 1.6 grams), as well as the administration of fibrinogen (1.5 grams vs 0.9 grams) and PCC (2.6 IU vs 0.7$)$.

Regarding the use of activated FVII, there was an increase in its use in the postoperative period with the implementation of the protocol, but it was only administered to 2 patients in the MHP group.

The application of the protocol was not associated with a higher incidence of adverse effects or complications related to massive transfusion, or even the eventual appearance of thrombotic phenomena associated with the increased administration of haemostatic drugs in the MHP group. However, and contrary to expectations, our results show an increase in the appearance of these phenomena in patients in the non-MHP group.

There was no decrease in postoperative bleeding after implementation of MHP. There was also no decrease in haemorrhagic events, both minor (32\% vs $13 \%$ ) and major ( $26 \%$ vs $7 \%$ ).

There was no higher incidence of immunological reactions in the MHP group, but lower. There was also no increase in non- 
immunological reactions, which occurred as well in a lower percentage in the MHP group.

We did not find a decrease in mortality in MHP patients (40\% vs. $21 \%)$. The publications on this subject are very variable, but there is agreement with other authors [10-13].

Adherence to the MHP as a whole was poor, largely due to difficulties in modifying "traditional" empirical therapeutic strategies. There was greater compliance in the initial phases of the protocol (including haemoderivatives, fibrinogen and prothrombinic complex) than in the final phases (cryoprecipitate and FVIIa). However, there were no significant differences in the cessation of bleeding in the first 24 hours between the groups.

In this study we observed a non-significant decrease in hospital stay in patients who followed MHP (16 days vs. 22 days), which has also been seen in other studies [14-15].

The main limitations of this study include the relatively small sample size, and the relatively low protocol adherence rate. In addition, the study was not randomised, so there is a possibility that the MHP tended to be activated for more severe patients.

Given the limitation of sample size and heterogeneity in the etiology and development of bleeding, we cannot conclude that there are significant differences in mortality between the two groups

\section{Conclusions}

Although the application of the protocol has not led to a decrease in the mortality rate, this does not differ from that reported in the literature and given the limitation of sample size and heterogeneity in the etiology and development of bleeding, we cannot conclude that there are significant differences in mortality between the two groups.

We could also consider it safe even though there was an increase in the administration of procoagulant factors since it was not associated with a higher incidence of adverse effects and complications related to mass transfusion.

The absence of viscoelastic tests could have influenced this increased consumption of procoagulant factor.

\section{References}

1. Hardy JF, de Moerloose P, Samama CM (2005) The coagulopathy of massive transfusion. Vox Sang. 89: 123-7 [Crossref]

2. Ferrara A, MacArthur JD, Wright HK, Modlin IM, McMillen MA (1990) Hypothermia and acidosis worsen coagulopathy in the patient requiring massive transfusion. Am J Surg. 160: 515-8. [Crossref]

3. Fernández-Hinojosa, F. Murillo-Cabezas, A. Puppo-Moreno, S.R. Leal-Noval (2012) "Treatment alternatives in massive hemorrhage", Med Intensiva 36: 496 503. [Crossref]

4. Borgman MA, Spinella PC, Perkins JG, Grathwohl KW, Repine T, Beekley AC, Sebesta J, Jenkins D, Wade CE, Holcomb JB (2007) "The ratio of blood products transfused affects mortality in patients receiving massive transfusions at a combat support hospital". J Trauma 63: 805-813. [Crossref]

5. Holcomb JB, Jenkins D, Rhee P, et al. (2007) "Damage control resuscitation: directly addressing the early coagulopathy of trauma". J Trauma. 62: 307-310. [Crossref]

6. Llau JV, Acosta FJ, Escolar G, Fernández-Mondéjar E, Guasch E, Marco P et al. (2015) Multidisciplinary consensus document on the management of massive haemorrhage (HEMOMAS document). Med Intensiva 39: 483-504. [Crossref]

7. National Blood Authority (NBA). (2011) "Patient Blood Management Guidelines: Module 1". Critical Bleeding /Massive Transfusion. Canberra, Australia: NBA;
8. Goodnough LT, Levy JH, Murphy MF (2013) Concepts of blood transfusion in adults. Lancet. 381 (9880): 1845-1854. [Crossref]

9. Holcomb JB, Fox EE, Zhang X, et al. (2013) PROMMTT Study Group. "Cryoprecipitate use in the PROMMTT study". J Trauma Acute Care Surg 75(Suppl 1): S31- [Crossref]

10. Greer SE, Rhynhart KK, Gupta R, Corwin HL (2010) "New developments in massive transfusion in trauma". Current opinion in anaesthesiology 23: 2 246-50. [Crossref]

11. O'Keeffe T, Refaai M, Tchorz K, Forestner JE, Sarode R (2008) "A massive transfusion protocol to decrease blood component use and costs". Arch Surg. 143: 686-90, discussion: 90-1. [Crossref]

12. Snyder CW, Weinberg JA, McGwin G, et al. (2009) "The relationship of blood product ratio to mortality: Survival benefit or survival bias?" J Trauma. 66: 358362. [Crossref]

13. Magnotti LJ, Zarzaur BL, Fischer PE, Williams RF, Myers AL, Bradburn EH, Fabian TC, Croce MA (2011) "Improved survival after hemostatic resuscitation: does the emperor have no clothes?". J Trauma 70: 97-102. [Crossref]

14. Sirat Khan, Shubha Allard, Anne Weaver, Colin Barber, Ross Davenport, Karim Brohi (2013) "A major haemorrhage protocol improves the delivery of blood component therapy and reduces waste in trauma massive transfusion". Mayo vol 44, Issue 5,pages 587-592. [Crossref]

15. Cotton BA, Au BK, Nunez TC, et al. (2009) "Predefined massive transfusion protocols are associated with a reduction in organ failure and postinjury complications". J Trauma 66: 41-9. [Crossref]

\section{Citation:}

González Fariña V, Martín Lorenzo MC1, Borges Jurado R2, Jiménez Rivera J3, Raya Sánchez JM4, Brouard MT3, Arribas-Carrión JC1, Montón Giménez N (2018) Observational Study to Assess the Safety and Clinical Effectiveness of the Hospital Universitario de Canarias Massive Transfusion Protocol. J Clin Res Med Volume 1(3): 1-7 